\title{
Pretransplant gastroesophageal reflux compromises early outcomes after lung transplantation
}

\author{
Sudish C. Murthy, MD, PhD, ${ }^{\mathrm{a}}$ Edward R. Nowicki, MD, MS, ${ }^{\mathrm{a}}$ David P. Mason, MD, ${ }^{\mathrm{a}}$ Marie M. Budev, DO, \\ MPH, ${ }^{\mathrm{b}}$ Anthony I. Nunez, MD, ${ }^{\mathrm{a}}$ Lucy Thuita, MS, ${ }^{\mathrm{c}}$ Jeffrey T. Chapman, MD, ${ }^{\mathrm{b}}$ Kenneth R. McCurry, MD, ${ }^{\mathrm{a}}$ \\ Gösta B. Pettersson, MD, PhD, and Eugene H. Blackstone, $\mathrm{MD}^{\mathrm{a}, \mathrm{c}}$
}

Objectives: Gastroesophageal reflux disease (GERD) is implicated as a risk factor for bronchiolitis obliterans syndrome after lung transplantation, but its effects on acute rejection, early allograft function, and survival are unclear. Therefore, we sought to systematically understand the time-related impact of pretransplant GERD on graft function (spirometry), mortality, and acute rejection early after lung transplantation.

Methods: From January 2005 to July 2008, 215 patients underwent lung transplantation; 114 had preoperative $\mathrm{pH}$ testing, and $32(28 \%)$ had objective evidence of GERD. Lung function was assessed by forced 1-second expiratory volume $\left(\mathrm{FEV}_{1}\right.$; percent of predicted) in 97 patients, mortality by follow-up (median, 2.2 years), and acute rejection by transbronchial biopsy.

Results: Pretransplant GERD was associated with decreased $\mathrm{FEV}_{1}$ early after lung transplantation $(P=.01)$ such that by 18 months, $\mathrm{FEV}_{1}$ was $70 \%$ of predicted in double lung transplant patients with GERD versus $83 \%$ among non-GERD patients $(P=.05)$. A similar decrease was observed in single lung transplantation $(50 \%$ vs $60 \%$, respectively; $P=.09)$. GERD patients had lower survival early after transplant $(P=.02)-$ $75 \%$ versus $90 \%$. Presence of GERD did not affect acute rejection $(P=.6)$.

Conclusions: For lung transplant recipients, pretransplant GERD is associated with worse early allograft function and survival, but not increased acute rejection. The compromise in lung function is substantial, such that $\mathrm{FEV}_{1}$ after double lung transplant in GERD patients approaches that of single lung transplant in non-GERD patients. We advocate thorough testing for GERD before lung transplantation; if identified, aggressive therapy early after transplant, including fundoplication, may prove efficacious. (J Thorac Cardiovasc Surg 2011;142:47-52)

\section{Supplemental material is available online.}

Gastroesophageal reflux has been implicated as a risk factor for late allograft dysfunction after lung transplantation. ${ }^{1,2}$ This association is strengthened by reports demonstrating that fundoplication early after transplantation has a protective effect from bronchiolitis obliterans syndrome (BOS). ${ }^{3}$ Indiscriminate fundoplication, however, has not

\footnotetext{
From the Heart and Vascular Institute, ${ }^{a}$ Department of Thoracic and Cardiovascular Surgery; Respiratory Institute, ${ }^{\mathrm{b}}$ Department of Pulmonary, Allergy, and Critical Care Medicine; and Research Institute, ${ }^{c}$ Department of Quantitative Health Sciences, Cleveland Clinic, Cleveland, Ohio.

This study was supported in part by the Peter and Elizabeth C. Tower and Family Endowed Chair in Cardiothoracic Research, James and Sharon Kennedy, the Slosburg Family Charitable Trust, and Stephen and Saundra Spencer (to G.P.B.), and the Kenneth Gee and Paula Shaw, PhD, Chair in Heart Research (to E.H.B.).

Disclosures: Authors have nothing to disclose with regard to commercial support.

Received for publication Feb 16, 2011; revisions received April 7, 2011; accepted for publication April 26, 2011.

Address for reprints: Sudish C. Murthy, MD, PhD, Department of Thoracic and Cardiovascular Surgery, Cleveland Clinic, 9500 Euclid Avenue/Desk J4-1, Cleveland, OH 44195, Phone: (216) 444-5640, Fax: (216) 636-1267 (E-mail: murthys1 @ccf. org).

$0022-5223 / \$ 36.00$

Copyright (C) 2011 by The American Association for Thoracic Surgery

doi:10.1016/j.jtcvs.2011.04.028
}

yet translated into an obvious survival advantage, and preservation of spirometry in this setting has not been evaluated. Consequently, the belief that reflux negatively affects outcome of transplantation is not yet universally accepted. Moreover, early impact of preexisting gastroesophageal reflux disease (GERD) has not been studied. Therefore, we sought to systematically understand the time-related impact of pretransplant GERD on graft function (spirometry), mortality, and acute rejection early after lung transplantation.

\section{PATIENTS AND METHODS}

From January 2005 to July 2008, 215 patients underwent lung transplantation at Cleveland Clinic. Beginning in 2005, an attempt was made to assess GERD and esophageal and gastric motility before listing for lung transplantation. It was not possible to test all patients because of acuity of illness, inability to tolerate assessment, and lack of payor authorization Although some of these tests were performed at Cleveland Clinic, in numerous cases they were performed at referring institutions because of these constraints. In total, 114 patients underwent at least ambulatory $\mathrm{pH}$ assessment, and they constitute the study group. No patient underwent fundoplication after transplant for the duration of the study. None was diagnosed with scleroderma preoperatively.

\section{Pretransplant GERD}

GERD was considered for this study as a dichotomous diagnosis because of heterogeneity of the raw data from multiple institutions. Some reports of 24-hour $\mathrm{pH}$ testing expressed the results as simply positive 


\section{Abbreviations and Acronyms}

BOS = bronchiolitis obliterans syndrome

$\mathrm{FEV}_{1}=$ forced 1-second expiratory volume

$\mathrm{FEV}_{1} \%=$ percent of predicted $\mathrm{FEV}_{1}$

GERD = gastroesophageal reflux disease

or negative for GERD without additional accompanying quantification. When quantitative data were available, GERD was defined as abnormalities of percent recumbent reflux, total time of recumbent and upright reflux, total number of reflux episodes in 24 hours, or elevated DeMeester score. There was no attempt to compare raw data between institutions because it was not possible to normalize across institutions. The lowest common expression from these 24-hour assessments was dichotomous: a diagnosis of GERD or no GERD. It was recommended that $\mathrm{pH}$ studies be performed after discontinuing acid suppressing medications for at least 24 hours.

\section{End Points}

Spirometry. Of the 114 patients, $97(85 \%)$ had at least 1 posttransplant measurement at Cleveland Clinic of forced 1-second expiratory volume $\left(\mathrm{FEV}_{1}\right)$, expressed as percent of predicted $\left(\mathrm{FEV}_{1} \%\right)$. A total of 871 assessments were available for analysis (Figure E1). These data were retrieved from the Pulmonary Function Laboratory Database. Median time to spirometry was 4.4 months (15th and 85 th percentiles; 1 and 13 months, respectively).

Survival. Follow-up was $100 \%$ complete for all-cause mortality after lung transplantation. A total of 212 patient-years of data were available for analysis, with a median follow-up of 2.2 years; $10 \%$ of patients were followed up for more than 3.3 years.

Acute rejection. All lung biopsy specimens were graded according to the Lung Rejection Study Group classification system. ${ }^{4,5}$ This study focused on perivascular rejection grades A0 through A4. Because of low prevalence of grades A2 and above, these were combined into 1 group for purposes of analysis. No patient in the study cohort had biopsy grade A4. Early humoral rejection was not interrogated in these patients. To reliably analyze the data and reduce confusion with BOS, we included biopsy specimens only up to 1.5 years after transplant.

These data were retrieved from Cleveland Clinic pathology reports and were recorded routinely in the Electronic Data Interface for Transplantation. A total of 725 biopsy records were available for 112 (98\%) patients, out of 114 who had a pH test result (Figure E2). The 2 patients with no biopsy results died on the 27th and 90th day posttransplant.

\section{Data}

Data from the the Electronic Data Interface for Transplantation, Pulmonary Function Laboratory Database, Pathology Database, and manually extracted GERD data were approved for use in research by the Cleveland Clinic Institutional Review Board, with patient consent waived.

\section{Data Analysis}

GERD associations. Variables associated with pretransplant GERD were identified by multivariable logistic regression using pretransplant variables only (Appendix E1) and a bagging variable selection strategy. ${ }^{6}$ In brief, automated stepwise regression was performed on 500 bootstrap data sets, retaining variables with $P \leq .05$. Variables appearing in $50 \%$ or more of the resulting 500 models (median rule) were considered reliable risk factors.

To risk adjust outcomes after transplantation, we augmented this model into a propensity model using variables occurring in $15 \%$ or more of boot- strap models. ${ }^{7-10}$ Variables identified by an asterisk in Appendix E1 were included in this semisaturated model. Thereafter, a propensity score was calculated for each patient for use in risk adjustment.

GERD and spirometry. The association of pretransplant GERD and posttransplant $\mathrm{FEV}_{1}$ was investigated using a nonlinear cumulative logit model with temporal decomposition into phases, ${ }^{11}$ with the assumption of multinomial distribution. Three phases of temporal trend were identified for the odds of no rejection: an early constant phase, early to intermediate peaking phase, and late rising phase, the latter approaching an asymptote about 18 months after transplant. The resulting patientspecific estimates were averaged to determine prevalence of each biopsy grade over time.

GERD and survival. Survival was assessed nonparametrically by the Kaplan-Meier method and parametrically by a multiphase hazard model. The parametric model was used to resolve phases of instantaneous risk of death (hazard function) and to estimate shaping parameters of each. ${ }^{12}$ (For additional details, see http://www.clevelandclinic.org/ heartcenter/hazard.) Survival was estimated for 2 groups: (1) patients in our study period (January 2005-July 2008), comparing those with and without $\mathrm{pH}$ test results (Figure E3), and (2) patients with GERD compared with no GERD. Effect of GERD on survival was assessed overall and after propensity adjustment.

GERD and acute rejection. Repeated measurements of acute rejection grade were analyzed longitudinally using nonlinear mixed modeling with temporal decomposition as described for spirometry.

Presentation. Continuous variables are summarized by mean \pm standard deviation unless distributions are skewed, in which case median and (for consistency) 15 th and 85 th percentiles are given. Regression coefficients are accompanied by \pm 1 standard error. For consistency, time-related estimates are accompanied by $68 \%$ confidence limits equivalent to \pm 1 standard error. Categorical variables are summarized by frequency and percentage.

\section{RESULTS \\ GERD Associations}

Of the patients with pretransplant $\mathrm{pH}$ testing $(\mathrm{n}=114)$, $32(28 \%)$ were identified as having GERD (Table 1). Only $3(9.4 \%)$ had GERD symptoms at transplant, although $7(22 \%)$ patients were receiving acid suppression therapy. Despite a thorough investigation of associated factors, including age, etiology of lung failure, smoking history, and body mass index, among others, no reliable associations with GERD were identified.

\section{GERD and Spirometry}

There was gradual improvement in $\mathrm{FEV}_{1} \%$ early after transplant that plateaued after about 6 months (Figure 1). Pretransplant GERD was associated with decreased $\mathrm{FEV}_{1}$ early after lung transplantation (Table E1). Specifically, by 18 months after transplant, pretransplant GERD was associated with a decrease of $\mathrm{FEV}_{1} \%$ from $83 \%$ in double lung transplant without GERD to $70 \%$ with GERD, and from $60 \%$ in single lung transplant without GERD to $50 \%$ with GERD (Figure 2). Apparently, maximum $\mathrm{FEV}_{1}$ for double lung transplant recipients with GERD is not demonstrably better than after single lung transplant for patients without GERD. The spirometry advantage of double lung transplant was importantly abrogated by GERD. Thus, the difference in $\mathrm{FEV}_{1}$ between them at 12 months was $70 \%$ versus $61 \%$. 
TABLE 1. Patient and transplant details according to presence or absence of pretransplant GERD

\begin{tabular}{|c|c|c|c|c|c|}
\hline \multirow[b]{2}{*}{ Characteristic } & \multicolumn{2}{|r|}{$\begin{array}{c}\text { GERD } \\
(\text { total } \mathbf{n}=\mathbf{3 2})\end{array}$} & \multicolumn{2}{|r|}{$\begin{array}{c}\text { No GERD } \\
(\text { total } \mathbf{n}=\mathbf{8 2})\end{array}$} & \multirow[b]{2}{*}{$P$ value } \\
\hline & $\mathbf{n}^{*}$ & No. $(\%)$ or mean \pm SD & $\mathbf{N}^{*}$ & No. $(\%)$ or mean \pm SD & \\
\hline \multicolumn{6}{|l|}{ Demographic } \\
\hline Women & 32 & $9(28)$ & 82 & $33(40)$ & .2 \\
\hline Age (y) & 32 & $56 \pm 13$ & 82 & $54 \pm 10$ & .02 \\
\hline BMI $\left(\mathrm{kg} \cdot \mathrm{m}^{-2}\right)$ & 32 & $25 \pm 4.3$ & 80 & $25 \pm 4.9$ & .6 \\
\hline \multicolumn{6}{|l|}{ Comorbidities } \\
\hline History of smoking & 32 & $23(72)$ & 82 & $56(68)$ & .7 \\
\hline Creatinine $\left(\mathrm{mg} \cdot \mathrm{dL}^{-1}\right)$ & 27 & $0.73 \pm 0.18$ & 73 & $0.75 \pm 0.23$ & .9 \\
\hline Diabetes & 25 & $4(16)$ & 64 & $11(17)$ & .9 \\
\hline \multicolumn{6}{|l|}{ Pulmonary function } \\
\hline Preoperative $\mathrm{FEV}_{1}(\%$ of predicted $\dagger)$ & 32 & $33 \pm 18$ & 81 & $32 \pm 17$ & .7 \\
\hline Etiology of lung failure & 32 & & 81 & & \\
\hline COPD or alpha-1 antitrypsin deficiency & & $15(47)$ & & $30(37)$ & .3 \\
\hline Idiopathic pulmonary fibrosis & & $11(34)$ & & $33(41)$ & .5 \\
\hline Cystic fibrosis or bronchiectasis & & $4(13)$ & & $12(15)$ & .8 \\
\hline Sarcoidosis & & $0(0)$ & & $2(2.5)$ & .4 \\
\hline Other & & $2(6.3)$ & & $4(4.9)$ & .8 \\
\hline \multicolumn{6}{|l|}{ Surgical } \\
\hline Double lung transplant & 32 & $17(53)$ & 82 & $59(72)$ & .06 \\
\hline Maximum ischemic time (min) & 31 & $297 \pm 81$ & 74 & $291 \pm 68$ & .9 \\
\hline
\end{tabular}

$\overline{G E R D}$, Gastroesophageal reflux disease; $S D$, standard deviation. $B M I$, body mass index; $F E V_{l}$, forced 1-second expiratory volume; $C O P D$, chronic obstructive pulmonary disease. *Patients with data available. $\dagger$ National Health and Nutrition Examination Survey normalized.

\section{GERD and Survival}

There were no evident differences in modes of death between GERD and no GERD patients, with infection, respiratory failure, and graft failure predominating (Table E2). Unadjusted survival after lung transplantation at $1,3,6$, and 12 months for patients without GERD was $99 \%, 94 \%, 90 \%$, and $87 \%$ versus $94 \%, 91 \%, 75 \%$, and $75 \%$ for patients with GERD
$(P[\log$-rank $]=.02 ;$ Figure 3$)$; however, events were too few to differentiate this as an early or late effect (Table E1).

\section{GERD and Acute Rejection}

Presence of pretransplant GERD did not affect acute rejection grade or freedom from rejection over the first 18 months after transplant (Table E1; Figure 4).

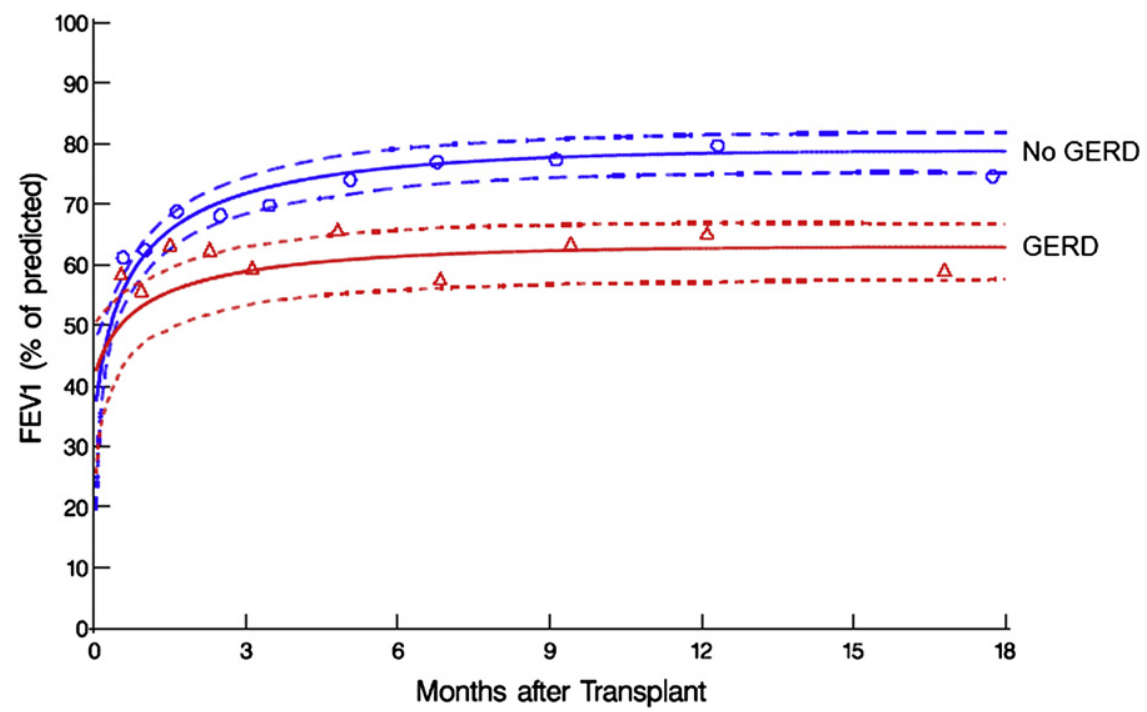

FIGURE 1. Estimated mean forced 1-second expiratory volume $\left(F E V_{l}\right)$ expressed as a percent of predicted, stratified by presence or absence of gastroesophageal reflux disease $(G E R D)$. Symbols represent crude depictions of raw data unadjusted for repeated measures. Dashed lines represent $68 \%$ confidence limits for the mean. 


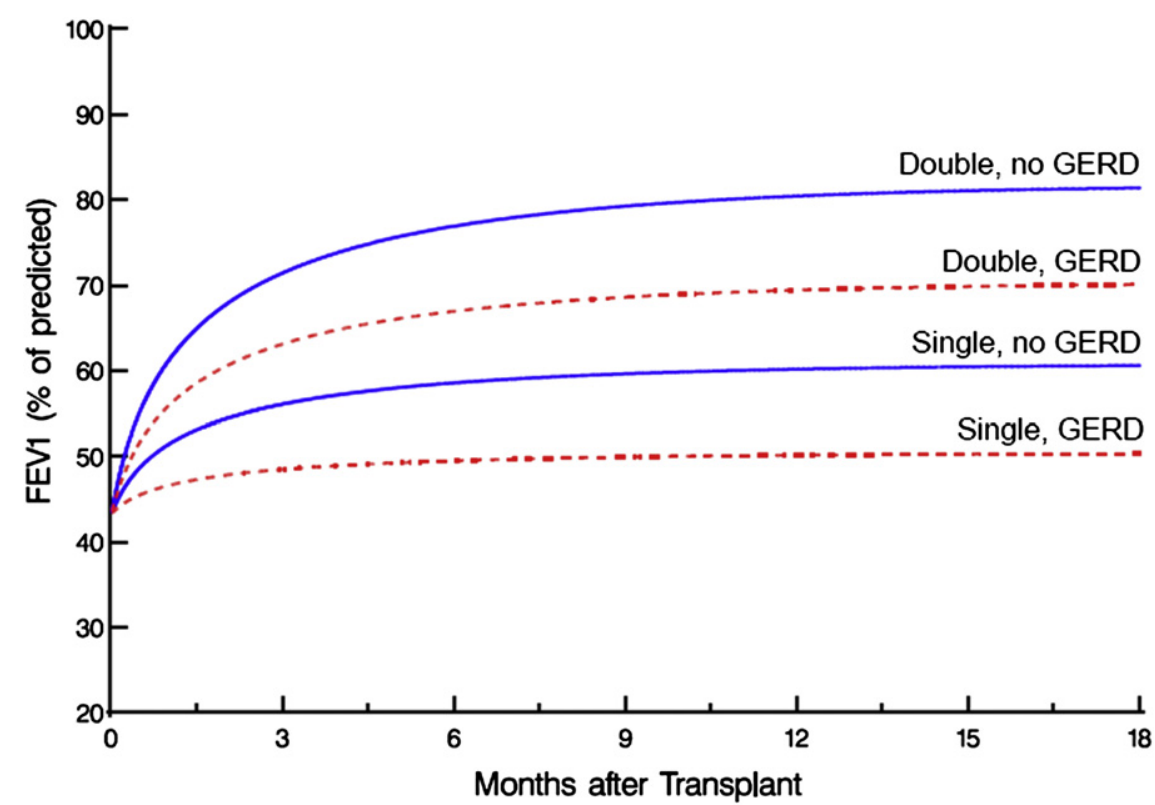

FIGURE 2. Estimated mean forced 1-second expiratory volume $\left(F E V_{l}\right)$ after lung transplantation according to double versus single lung transplant and presence or absence of gastroesophageal reflux disease (GERD).

\section{DISCUSSION}

Pretransplant GERD is associated with deleterious early outcomes after lung transplantation. These early effects are manifested principally as a marked decrease in maximum posttransplant $\mathrm{FEV}_{1} \%$ and higher 1-year mortality. These findings suggest that preexisting GERD might serve as a critical inflection point around which therapeutic intervention might importantly improve lung transplant outcome.

The mechanism of the process, surprisingly, does not appear to involve an increase in acute rejection frequency or severity, as has been suggested by others. ${ }^{1-3}$ However, the present study differs because of pretransplant and not posttransplant assessment of GERD, and the analysis accounted for results from every single spirometric test and biopsy performed after transplant. Furthermore, effect of pretransplant GERD does not appear to be associated with age, etiology of lung failure, or whether a single or double lung transplant was performed.

A high prevalence of GERD in patients with end-stage lung disease, particularly those awaiting pulmonary

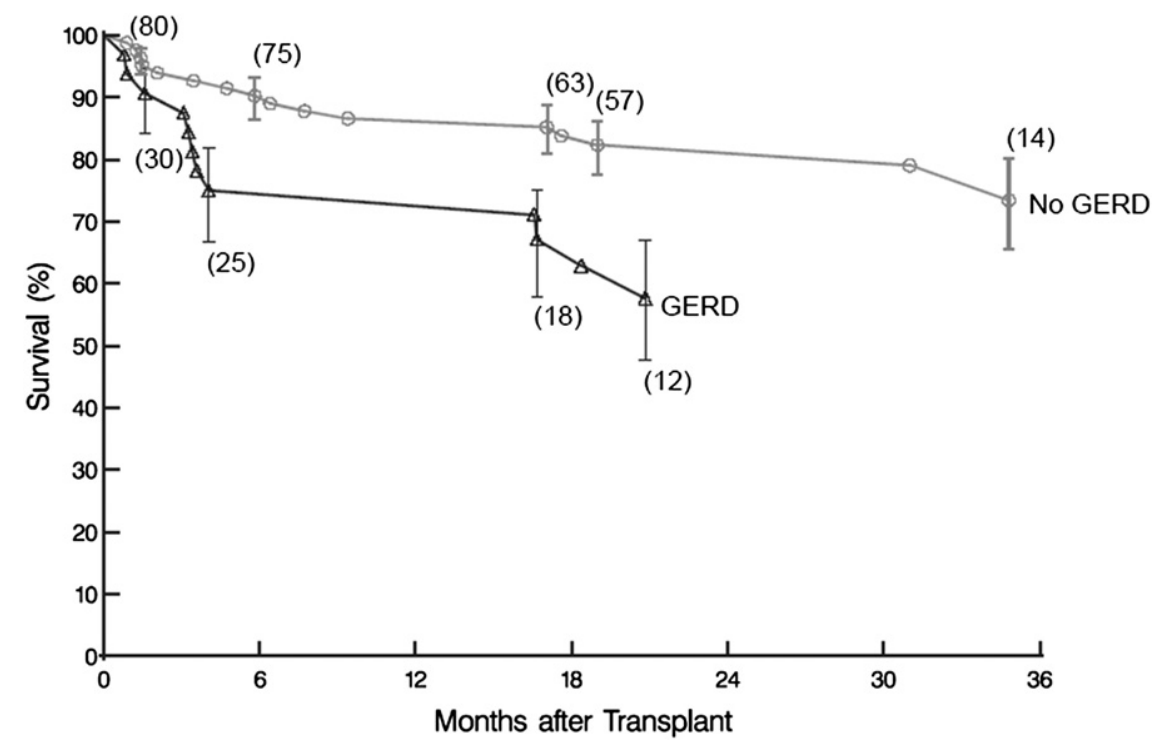

FIGURE 3. Survival after lung transplantation according to presence or absence of gastroesophageal reflux disease (GERD). Each symbol represents a death, vertical bars confidence limits equivalent to \pm 1 standard error, and numbers in parentheses patients remaining at risk. 


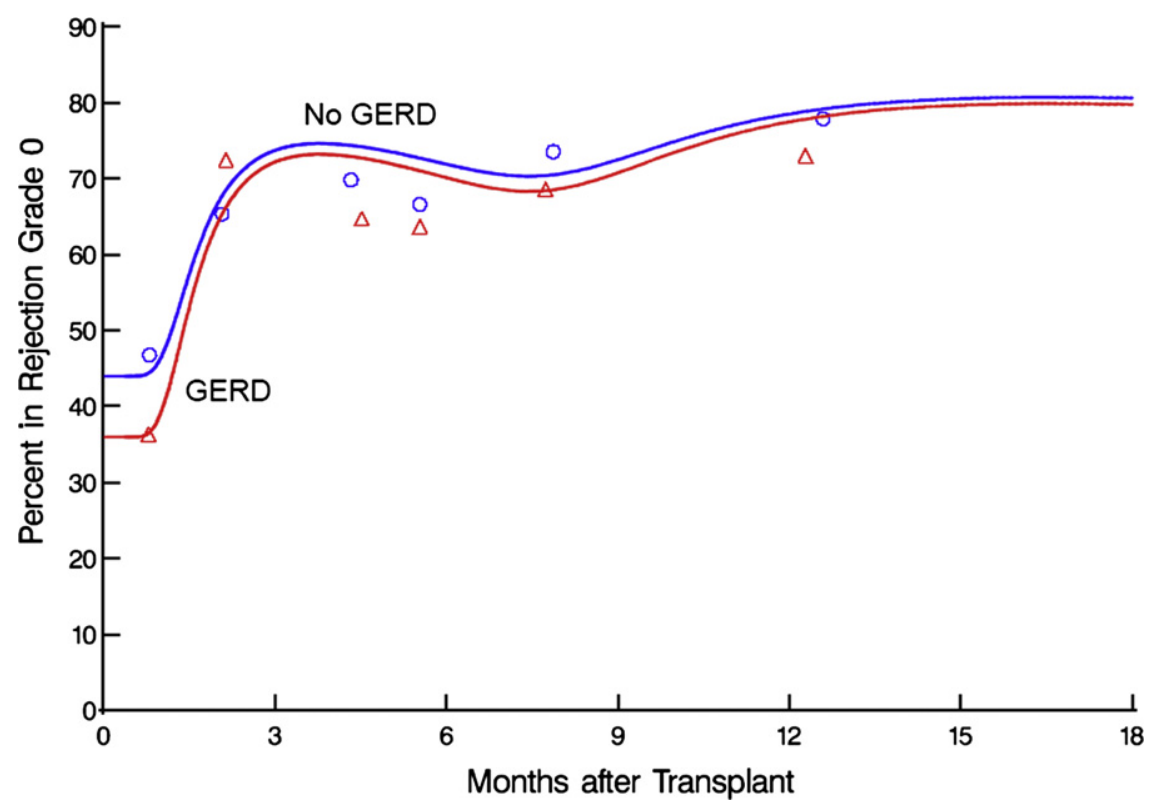

FIGURE 4. Proportion of patients in vascular rejection grade 0 after lung transplantation according to presence or absence of gastroesophageal reflux disease (GERD). The format is as in Figure 1, except confidence bands have been suppressed for clarity.

transplantation, is well documented. ${ }^{13,14}$ This, in combination with appreciation that reflux is common after transplant and linked to BOS, suggests that it may be an important mediator of chronic lung injury before transplant and play a role in the complex cascade of events leading to allograft dysfunction after transplant. Mounting evidence supports a central role for GERD in lung injury; that fundoplication both before and after lung transplant appears beneficial clearly strengthens this contention. ${ }^{15}$ Although it is unknown whether reflux identified before transplant faithfully translates after transplant, our results suggest it probably does.

Prevalence of pretransplant GERD in this series is consistent with that reported elsewhere ${ }^{14}$ but far below that reported after lung transplantation. ${ }^{1}$ There are likely multiple reasons for this, including iatrogenic vagal nerve injury, medications, and pleural pressure changes after transplant. Esophageal dysmotility, lower esophageal sphincter relaxation, and delayed gastric emptying might all collaborate to magnify preexisting GERD after transplant or create the process de novo. Pretransplant symptoms of GERD did not correlate well with objective assessments or with use of acid suppression therapy and should not be used as a surrogate for GERD after transplant.

In light of these "difficult-to-quantify" factors potentially arising after transplant, it was surprising to us that pretransplant GERD still emerged as such an important predictor of outcome. Our initial plan was to reassess GERD after transplant, allowing us to understand the process more thoroughly and better appreciate the contribution of the transplant to GERD. However, it quickly became ap- parent that postoperative reflux studies were even more difficult to obtain than preoperative ones for many of the same reasons detailed in the "Methods" section. It is our belief that posttransplant assessment would be far more informative; however, its timing becomes complicated given the highly variable postoperative course of patients, especially as preoperative acuity of illness has increased with the lung allocation score system. The impact of pretransplant GERD is an early phenomenon, and although our $\mathrm{pH}$ measurements clearly highlighted a population at risk, more accurate information about patients at risk after transplant is critical.

We have not adopted broad application of fundoplication early after transplant. Fundoplication, even if performed laparoscopically, is a substantial undertaking. When fundoplication has been performed after lung transplantation by others, few procedures occurred in the first 3 months. ${ }^{16}$ In the cohort of patients for whom posttransplant fundoplication was found to retard development of BOS, $\mathrm{pH}$ testing was obtained an average of 500 days after transplant. ${ }^{1} \mathrm{Be}-$ cause our findings suggest an early impact of GERD (within the first year), this phenomenon was likely perhaps not addressed in any prior study.

Even now, when pretransplant GERD is identified, we have reserved fundoplication for patients in whom the trajectory of postoperative $\mathrm{FEV}_{1}$ has probably plateaued. This has resulted in few posttransplant fundoplications, most often in the setting of large hiatal hernias. Perhaps it is time to revisit this treatment strategy and become more aggressive.

Impact of pretransplant GERD on development of BOS is unclear, and longer follow-up of our cohort is necessary to 
gain insight into this relationship. The difference in $\mathrm{FEV}_{1}$ reference point between patients with and without GERD may factor into future diagnosis of BOS because, currently, there is no accounting for the decrement in spirometry expected for patients with GERD.

The study suggests that pretransplant GERD may negatively affect survival. It is reasonable to believe that this is mediated by a direct effect of GERD on allograft function, as has been demonstrated. Depending on the actual mechanism, it is conceivable that presence of GERD lessens the survival advantage of double over single lung transplant that has been reported. ${ }^{17}$

The mechanism of graft dysfunction in patients with pretransplant GERD is unclear. We have examined a variety of possible culprits, including rejection, but have found none that appears to be associated with GERD. Whether this reflects inadequacy of our histopathologic characterization of biopsy specimens or whether early rejection and the phenomenon we are reporting are truly 2 distinct entities remains undetermined. Correlation of biopsy results with bronchoalveolar lavage specimens (bile) might clarify an association with declining spirometry. Humoral rejection was not interrogated in these patients and cannot be commented on.

\section{Limitations}

Reflux studies were not obtained on all transplant candidates, nor were they obtained at similar intervals from transplant in those patients studied. We have assumed that regardless of time interval to transplant, patients were not identified as transient refluxers, but rather as chronically afflicted. There may have been a subtle bias in the selection of patients able to be assessed for reflux (Figure E3), as well as institutional differences in $\mathrm{pH}$ testing. We attempted to control the latter by distilling the data down to a dichotomous variable: reflux yes-no. We appreciate that quantitative data for all patients would have been ideal. However, even at our own institution, where quantitative data accompany each $\mathrm{pH}$ study, a final gastroenterology interpretation was recorded as reflux yes-no. Lack of quantitative data is a limitation, particularly in terms of the depth of analysis that was possible. Additional markers for reflux, such as manometry and gastric emptying studies, although obtainable at our own institution, were rarely available from referring centers. Clearly, addition of these contributors to reflux would have enhanced this study.

This study highlights the importance, yet difficulties, of routine pretransplant GERD testing. Because of the findings, we have become more fastidious regarding collecting these important data and have begun to use endoscopic capsule assessment among patients with intractable cough to reduce errors or noncompliance encountered with conventional $\mathrm{pH}$ pretransplant testing.

\section{CONCLUSIONS}

For lung transplant recipients, pretransplant GERD is associated with worse early allograft function and survival, but not increased perivascular acute rejection. The compromise in lung function is substantial, such that $\mathrm{FEV}_{1}$ after double lung transplant in GERD patients approaches that of single lung transplant in non-GERD patients. We advocate thorough testing for GERD before lung transplantation; if identified, aggressive therapy early after transplant, including fundoplication, may prove efficacious.

\section{References}

1. Davis RD Jr, Lau CL, Eubanks S, Messier RH, Hadjiliadis D, Steele MP, et al. Improved lung allograft function after fundoplication in patients with gastroesophageal reflux disease undergoing lung transplantation. J Thorac Cardiovasc Surg. 2003;125:533-42.

2. Shah N, Force SD, Mitchell PO, Lin E, Lawrence EC, Easley K, et al. Gastroesophageal reflux disease is associated with an increased rate of acute rejection in lung transplant allografts. Transplant Proc. 2010;42:2702-6.

3. Cantu E 3rd, Appel JZ 3rd, Hartwig MG, Woreta H, Green C, Messier R, et al. J. Maxwell Chamberlain Memorial Paper. Early fundoplication prevents chronic allograft dysfunction in patients with gastroesophageal reflux disease. Ann Thorac Surg. 2004;78:1142-51; discussion 1151.

4. Knoop C, Estenne M. Acute and chronic rejection after lung transplantation. Semin Respir Crit Care Med. 2006;27:521-33.

5. Yousem SA, Berry GJ, Cagle PT, Chamberlain D, Husain AN, Hruban RH, et al. Revision of the 1990 working formulation for the classification of pulmonary allograft rejection: Lung Rejection Study Group. J Heart Lung Transplant. 1996; 15:1-15.

6. Breiman L. Bagging predictors. Machine Learning. 1996;24:123-40.

7. Rosenbaum PR, Rubin DB. The central role of the propensity score in observational studies for causal effects. Biometrika. 1983;70:41-55.

8. Rubin DB. The design versus the analysis of observational studies for causal effects: parallels with the design of randomized trials. Stat Med. 2007;26:20-36.

9. Blackstone EH. Comparing apples and oranges. J Thorac Cardiovasc Surg. 2002;123:8-15.

10. Drake C, Fisher L. Prognostic models and the propensity score. Int J Epidemiol. 1995;24:183-7.

11. Gillinov AM, Bhavani S, Blackstone EH, Rajeswaran J, Svensson LG, Navia JL, et al. Surgery for permanent atrial fibrillation: impact of patient factors and lesion set. Ann Thorac Surg. 2006;82:502-14.

12. Blackstone EH, Naftel DC, Turner ME Jr. The decomposition of time-varying hazard into phases, each incorporating a separate stream of concomitant information. J Am Stat Assoc. 1986;81:615-24

13. Button BM, Roberts S, Kotsimbos TC, Levvey BJ, Williams TJ, Bailey M, et al. Gastroesophageal reflux (symptomatic and silent): a potentially significant problem in patients with cystic fibrosis before and after lung transplantation. J Heart Lung Transplant. 2005;24:1522-9.

14. D'Ovidio F, Singer LG, Hadjiliadis D, Pierre A, Waddell TK, de Perrot M, et al. Prevalence of gastroesophageal reflux in end-stage lung disease candidates for lung transplant. Ann Thorac Surg. 2005;80:1254-60.

15. Linden PA, Gilbert RJ, Yeap BY, Boyle K, Deykin A, Jaklitsch MT, et al. Laparoscopic fundoplication in patients with end-stage lung disease awaiting transplantation. J Thorac Cardiovasc Surg. 2006;131:438-46.

16. Gasper WJ, Sweet MP, Hoopes C, Leard LE, Kleinhenz ME, Hays SR, et al. Antireflux surgery for patients with end-stage lung disease before and after lung transplantation. Surg Endosc. 2008;22:495-500.

17. Mason DP, Rajeswaran J, Murthy SC, McNeill AM, Budev MM, Mehta AC, et al. Spirometry after transplantation: how much better are two lungs than one? Ann Thorac Surg. 2008;85:1193-201. 201 e1-2. 
APPENDIX E1. Patient variables used in analysis*

\begin{tabular}{ll}
\hline Demographic & Gender, age $(\mathrm{y}),{ }^{*}$ body mass index $\left(\mathrm{kg} \cdot \mathrm{m}^{-2}\right),{ }^{*}$ race \\
Comorbidities & Smoking, creatinine $\left(\mathrm{mg} \cdot \mathrm{dL}^{-1}\right),{ }^{*}$ diabetes, hypertension \\
Serology & Blood type $(\mathrm{A}, \mathrm{AB}, \mathrm{B}, \mathrm{O}, \mathrm{Rh}+)$, panel reactive antibody \\
Hemodynamics & Cardiac output $\left(\mathrm{L} \cdot \mathrm{min}^{-1}\right)$, cardiac index $\left(\mathrm{L} \cdot \mathrm{min}^{-1} \cdot \mathrm{m}^{-2}\right)$, blood pressure (diastolic, ${ }^{*}$ systolic, ${ }^{*}$ mean; $\left.\mathrm{mm} \mathrm{Hg}\right)$, pulmonary \\
& $\quad$ arterial pressure $($ diastolic, systolic, mean; $\mathrm{mm} \mathrm{Hg})$ \\
Pulmonary function & Preoperative $\mathrm{FEV}_{1}(\%$ of predicted) \\
Diagnosis & Cystic fibrosis/bronchiectasis, chronic obstructive pulmonary disease/emphysema/alpha-1 antitrypsin deficiency, ${ }^{*}$ idiopathic \\
& pulmonary fibrosis* \\
Surgical & Double lung transplant, ischemic time (min) \\
Experience & Interval from listing to transplant $(\mathrm{d})$, interval from January 1,2005 to transplant $(\mathrm{y})^{*}$ \\
\hline
\end{tabular}

*Asterisks indicate variables included in semisaturated propensity model.

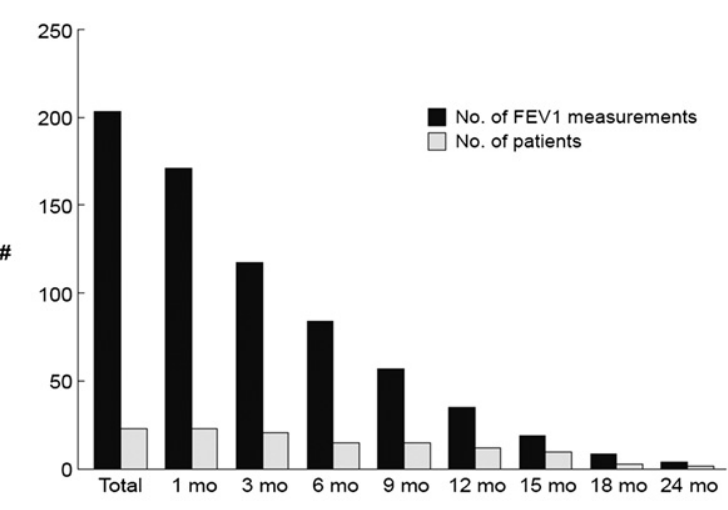

$\begin{array}{lllllllllll}\% \text { of patients } & 72 & 72 & 66 & 47 & 47 & 38 & 31 & 9 & 6\end{array}$

A

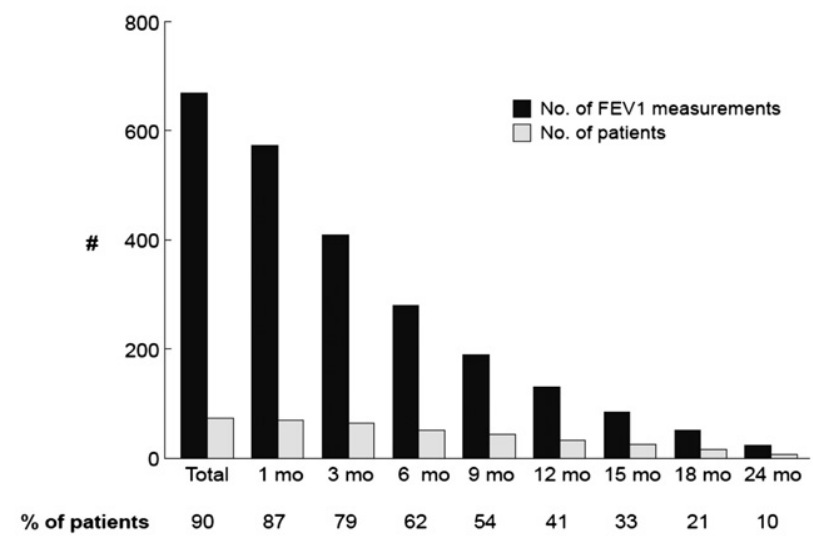

B

FIGURE E1. Number of patients with forced 1-second expiratory volume $\left(F E V_{1}\right)$ measurements available at and beyond various time points, and number of $\mathrm{FEV}_{1}$ measurements available for analysis. A, Patients with gastroesophageal reflux disease. B, Patients without gastroesophageal reflux disease.

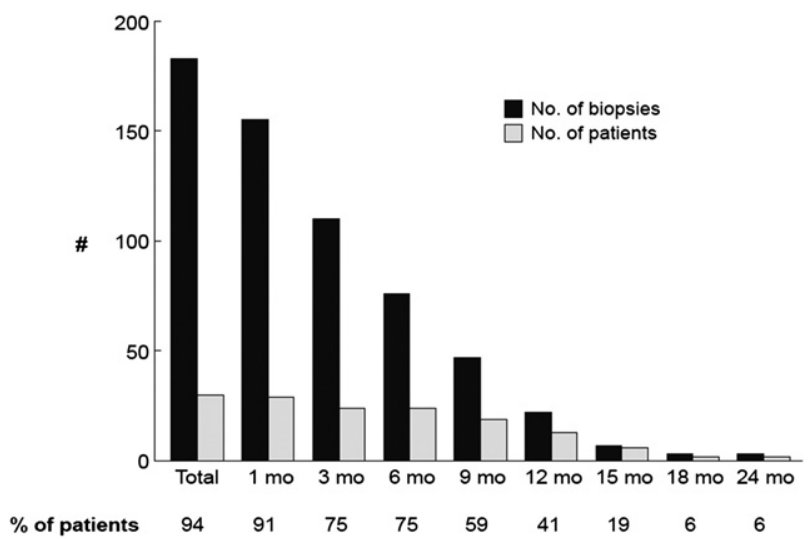

A

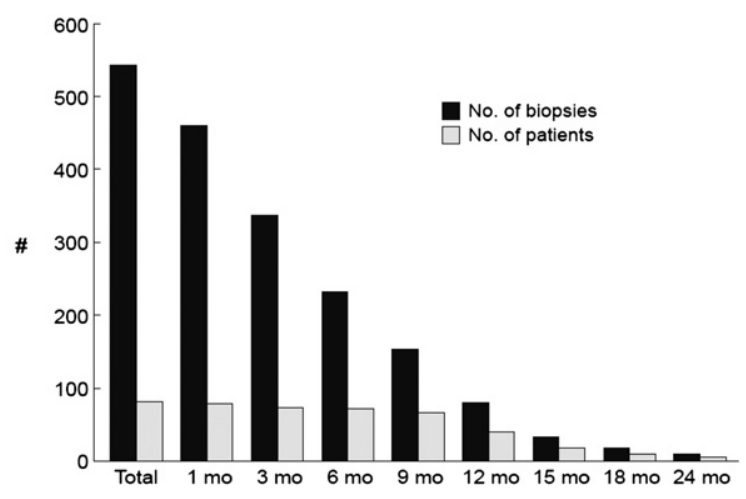

$\begin{array}{lllllllllll}\% \text { of patients } & 100 & 96 & 90 & 88 & 80 & 50 & 22 & 12 & 7\end{array}$

B

FIGURE E2. Number of patients with biopsy tissue available at and beyond various time points, and number of biopsy results available for analysis. Also shown is percentage of evaluable patients with biopsies. A, Patients with gastroesophageal reflux disease. B, Patients without gastroesophageal reflux disease. 


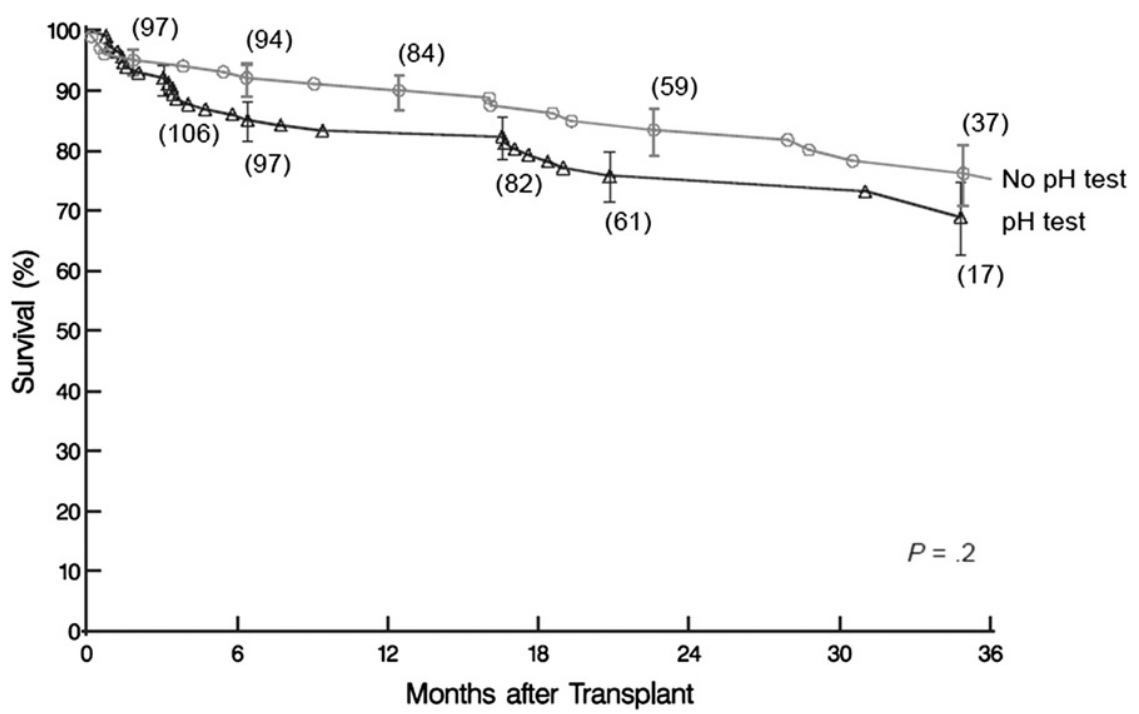

FIGURE E3. Survival after lung transplantation according to $\mathrm{pH}$ test availability. Format is as in Figure 4. 
TABLE E1. Unadjusted and propensity score-adjusted outcomes after lung transplantation in patients with and without GERD

\begin{tabular}{|c|c|c|c|}
\hline Phase & Variable & Estimate $\pm \mathrm{SE}$ & $\begin{array}{c}P \\
\text { value }\end{array}$ \\
\hline \multicolumn{4}{|l|}{$\mathrm{FEV}_{1}$} \\
\hline \multicolumn{4}{|l|}{ Unadjusted } \\
\hline Early & GERD & $-0.64 \pm 0.20$ & .001 \\
\hline Constant & GERD & $0.15 \pm 0.40$ & .7 \\
\hline \multicolumn{4}{|c|}{ Propensity adjusted } \\
\hline Early & GERD & $-0.56 \pm 0.20$ & .01 \\
\hline Constant & GERD & $-0.11 \pm 0.10$ & .9 \\
\hline \multicolumn{4}{|c|}{$\mathrm{FEV}_{1}$ and type of transplant } \\
\hline \multicolumn{4}{|c|}{ Unadjusted } \\
\hline \multirow[t]{3}{*}{ Early } & GERD and SLTx & $-0.91 \pm 0.50$ & .09 \\
\hline & GERD and DLTx & $-0.41 \pm 0.20$ & .1 \\
\hline & No GERD and DLTx & $-0.81 \pm 0.20$ & $<.0001$ \\
\hline \multirow[t]{3}{*}{ Constant } & GERD and SLTx & $-0.071 \pm 0.10$ & .6 \\
\hline & GERD and DLTx & $0.021 \pm 0.10$ & .8 \\
\hline & No GERD and DLTx & $-0.022 \pm 0.10$ & .9 \\
\hline \multicolumn{4}{|c|}{ Propensity adjusted } \\
\hline \multirow[t]{3}{*}{ Early } & GERD and SLTx & $-0.79 \pm 0.50$ & .1 \\
\hline & GERD and DLTx & $0.43 \pm 0.20$ & .09 \\
\hline & No GERD and DLTx & $0.81 \pm 0.10$ & $<.0001$ \\
\hline \multirow[t]{3}{*}{ Constant } & GERD and SLTx & $-0.091 \pm 0.10$ & .5 \\
\hline & GERD and DLTx & $0.021 \pm 0.10$ & .9 \\
\hline & No GERD and DLTx & $-0.022 \pm 0.10$ & .9 \\
\hline \multicolumn{4}{|l|}{ Survival } \\
\hline \multicolumn{4}{|l|}{ Unadjusted } \\
\hline Early & GERD & $0.91 \pm 0.60$ & .1 \\
\hline Late & GERD & $0.74 \pm 0.70$ & .3 \\
\hline \multicolumn{4}{|c|}{ Propensity adjusted } \\
\hline Early & GERD & $0.60 \pm 0.50$ & .2 \\
\hline Late & GERD & $1.07 \pm 0.90$ & .3 \\
\hline \multicolumn{4}{|l|}{ Rejection } \\
\hline \multicolumn{4}{|l|}{ Unadjusted } \\
\hline Early & GERD & $-0.22 \pm 0.40$ & 6 \\
\hline Late & GERD & $0.32 \pm 0.30$ & .3 \\
\hline \multicolumn{4}{|c|}{ Propensity adjusted } \\
\hline Early & GERD & $-0.55 \pm 0.40$ & .9 \\
\hline Late & GERD & $0.14 \pm 0.30$ & 6 \\
\hline
\end{tabular}

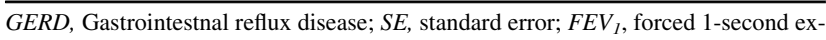
piratory volume; $S L T x$, single lung transplant; $D L T x$, double lung transplant.
TABLE E2. Mode of death after lung transplantation

\begin{tabular}{lccccc}
\hline & \multicolumn{2}{c}{ GERD } & & \multicolumn{2}{c}{ No GERD } \\
\cline { 2 - 3 } \cline { 5 - 6 } Primary mode of death & No. & \% of 12 & & No. & \% of 16 \\
\hline Infection & 4 & 33 & & 3 & 19 \\
Respiratory failure & 3 & 25 & & 3 & 19 \\
Graft failure & 1 & 8.3 & & 12 \\
Cardiac arrest & 1 & 8.3 & & 6.2 \\
Cancer & 0 & & 2 & 12 \\
Bronchiolitis & 1 & 8.3 & & \\
Multisystem organ failure & 1 & 8.3 & & \\
Graft dehiscence & 0 & & & 1 & 6.2 \\
Pulmonary embolism & 0 & & & 6.2 \\
Hemorrhage & 1 & 8.3 & & 0 \\
Unspecified & 0 & & 3 & 19 \\
Total & 12 & 100 & 16 & 100 \\
\hline
\end{tabular}

